Trabajos de Prehistoria

48, 1991, pp. $165-185$

\title{
LA GEOGRAFIA DEL PAISAJE Y EL TERRITORIO CULTURAL DE LOS MILLARES
}

\author{
POR \\ FRANCESC GUSI I JENER (*) \\ CARME OLARIA I PUYOLES $\left({ }^{* *}\right)$
}

RESUMEN La falta de estudios relacionados con una arqueogeografía del territorio cultural del grupo social de Los Millares no permite valorar debidamente las interrelaciones estrechas existentes entre una estructura socio-económica y el medio geográfico en donde se desarrolla. Aún a pesar de los escasos datos paleoambientales que se poseen de los distintos asentamientos pertenecientes a la Cultura de Los Millares, los autores piensan que existió una mayor pluviosidad, así como también una más amplia cobertura forestal en todo el territorio de la Andalucía oriental y Murcia, y por tanto una climatología y paisaje geográfico distintos al actual.

Por otro lado, la historia de la investigación en la Geografía, se polarizó desde sus origenes en torno a quienes deseaban que esta disciplina se conectase estrechamente con la antropología y la historia, y de aquellos otros autores que creían que su estudio debía incidir en aspectos puramente fisiográficos, independientemente de la acción humana en el medio natural.

También se subraya la falta de una mayor cooperación entre arqueólogos y geógrafos a la hora de enfocar conjuntamente problemas de investigación en áreas territoriales ocupadas durante los períodos culturales desarrollados a lo largo del Holoceno. Por otra parte, la aparición de la Arqueología Espacial como corriente de investigación ligada a la geografía del territorio y las distintas posiciones ideológicas y metodológicas de la arqueología prehistórica, muchas veces muy semejantes a las suscitadas entre los geógrafos, permiten paralelizar muchos aspectos de ambas disciplinas, ligadas estrechamente a las ciencias de la Tierra y el Hombre.

RESUME L'absence d'études en relation a une archéogeographie du territoire culturel du groupe social de Los Millares, ne permet pas évaluer comme il faut les interrelations très proches existentes entre une structure socio-économique et le milieu géographique où se déroule. Malgré les données insuffisants du paleoenvironement qui se possédent sur tous les différents établissements qui appartient a la Culture de Los Millares, à l'avis des les auteurs il y avait une plus grande pluviosité, même une plus ample coverture forestier dans tout le territoire de l'Andalousie orientale et Murcia, et

(`) Servei d'Investigacions Arqueológiques i Prehistóriques. Diputació de Castelló.

(“) Universitat Jaume I de Castelló. 
pourtant une climatologie et un paysage géographique tout différent à l'actuel. D'une autre coté, l'histoire de la recherche dans la Géographie s'avait polarisée depuis ses origines autour de ceux qui dessiraient que cette discipline fut plus proche à l'anthropologie et l'histoire, en face d'autres auteurs qui croyaient que son étude devait aborder des aspects simplement physiographiques, indépendamment de l'action humaine dans le milieu natural.

On souligne aussi l'absence d'une coopération entre les archéologues et les géographes, pour étudier ensemble les problèmes de la recherche à propos des territoires ocuppés pendant les periodes culturelles correspondant à l'Holocene. D'autre part l'apparition de l'Archéologie Spatial, comme une tendance de la recherche attachée a la géographie du territoire et les différents positions idéologiques et méthodologiques de l'archeologie préhistorique, fréquemment ressemblables à celles qui ont été suscitées pour les géographes, permetent comparer beaucoup d'aspects de cettes disciplines, liées étroitement à les sciences de la Terre et de l'Homme.

Palabras clave Arqueogeografía. Geografía Humana. Arqueologia Espacial. Cambios climáticos. Territorio cultural. Grupo social. Cultura de Los Millares. Calcolítico. Región sudoriental de la Peninsula Ibérica.

Mots clée Archeogéographie. Géographie Humaine. Archéologie Spatial. Changements Climatiques. Territoire Culturel. Groupe Social. Culture de Los Millares. Chalcolithique. Region sudoriental de la Péninsule Ibérique.

En el estado actual de la investigación prehistórica, la esọsez de estudios no sólo generales, sino también monográficos o específicos con respecto a una paieogeografía o arqueogeografía cultural de la región sudoriental de la Península Ibérica que nos informe respecto del medio natural donde se desarrolló la cultura de Los Millares a lo largo del III milenio, agrava considerablemente la visión y comprensión del desarrollo real de dicha formación socio-económica (Cuenca y Walker, 1977).

La cooperación interdisciplinar de diversas especialidades provenientes del campo de las Ciencias de la Tierra, como puedan ser la sedimentología, pedología, arqueogeomorfología, arqueobotánica, antracología, carpología, palinología y arqueozoología, entre otras, permiten reconstruir modelos destinados al estudio de la fisiografía y el medio natural dentro de la geografía humana, especialmente en los campos de la arqueogeografía, antropogeografía-geografía cultural, y geografía socialgeografía morfológica o etnográfica, todos los cuales dentro de sus diversos posicionamientos ideológicos, proporcionan nuevas conceptualizaciones y valiosos esquemas de trabajo a los prehistoriadores. La numerosa lista de geógrafos empeñados en tales objetivos está representada por figuras señeras en esta ciencia, tales como Ratzel (1882, 1891), Schlüeter (1906), Hoke (1907), Vallaux (1911), Bobek (1948), Hahn (1957), Sorre (1962), Bartels (1968), Schöller (1969), Wirth (1969), Hottes (1970), Claval (1973), etc.

Evidentemente no podemos participar en la polémica epistemológica e ideológica existente entre las distintas concepciones en liza, dentro de las corrientes actuales de los geógrafos, con el fin de establecer los paradigmas necesarios en la geografía humana o social contemporánea, pero sí, como arqueólogos, hemos de estar plenamente de acuerdo con quienes propugnan que la geografía se convierta en una morfología del paisaje cultural, como ya preconizaba Hettner (1927), y cuya modelación provendría de la actividad de los grupos sociales humanos.

El geógrafo francés Vidal de la Blache (1911) señala por primera vez la concepción ecológicocultural de la geografía, dentro de la cual se deberá estudiar la Tierra como el asentamiento del hombre y los modos de vida que se han desarrollado en ella, en una palabra, estudiarla como resultado del enfrentamiento del hombre con la naturaleza que lo rodea. Dentro de esta línea de pensamiento podemos encuadrar, entre otros, a Claval $(1973,1974)$, Buttimer $(1967,1968)$, y Quani (1981).

La arqueología territorial o espacial no deja de ser la consecuencia lógica de tales concepciones, cuyo objetivo no es sino enmarcar dentro de un método, tanto a la arquelogía como a la geografía 
humana, ya que la finalidad de ambas disciplinas es estudiar conjuntamente el hombre, el medio y los modos de vida de las formaciones socio-económicas, ya que son los principales conformadores del espacio dentro de la fisiografía de un territorio o región naturales. Así pues, ambas disciplinas se hallan empeñadas en un objetivo teórico común, la dimensión social, cuyo estudio permite explicar el paisaje cultural en diacronía y sincronia. Por su parte, el estudio funcional o económico del paisaje a través de la actividad humana fue una de las mejores aportaciones de Bobek $(1942,1948)$ y Christaller (1933, 1938), y cuyos seguidores más representativos en la actualidad son Haggett (1965), Everson y FitzGerald (1969), Hodder y Orton (1976), Bunge (1962), Chorley y Haggett (1967), gracias a los cuales sus aplicaciones se pueden adaptar a la investigación arqueológica. En nuestro país, la celebración en Teruel de los coloquios dedicado a la arqueología espacial (Seminario de Arqueología y Etnología Turolense- C.U.T., 1984, 1986, 1989), y también el realizado en Portugal, en las ciudades de Lisboa y Tomar (Seminario de Arqueología y Etnología Turolenses - C.U.T., 1988) abrió una importante etapa de renovación metodológica y conceptual, y aunque la orientación de los trabajos aportados se basaba en una perspectiva de la geografía territorial, poblacional y económica, interpretada por arqueólogos y prehistoriadores, no por ello debe ser obviada por quienes trabajan en el campo de la geografía humana o social.

Forzosamente en esta breve referencia a las tendencias "antropológicas» en la geografía, omitimos numerosas y contrapuestas teorías, ya que no es nuestra intención profundizar en dicha temática, sino únicamente esbozar una muy amplia visión de la misma, a fin de encuadrar y señalar el interés mutuo y la convergencia de necesidades, a la hora de elaborar modelos teóricos afines entre dos ciencias aparentemente distanciadas entre sí.

Al decir de Rühl (1938), la geografía humana se vincula a las ciencias sociales, en tanto que la geografía física pretende otros objetivos más "geológicos». Vemos pues, la profunda conexión de intereses científicos existentes entre arqueólogos, antropólogos y geógrafos, a fin de crear modelos teóricos que atañen a objetivos comunes dentro del marco de las ciencias históricas y sociales. Por ello, estamos totalmente de acuerdo con Hartshorne cuando opina que la Geografía puede ser una definición e interpretación de la Tierra como el mundo del Hombre.

En nuestra opinión, esta visión de la Geografía es de suma importancia para el estudio de la región sudoriental de la Península Ibérica por ejemplo, y cuya aplicación nos podría mostrar el funcionamiento del medio natural en donde se desarrolló, a lo largo del III milenio, la Cultura de Los Millares, lo cual nos permitiría obtener una mayor visión y comprensión, no sólo del desarrollo de este grupo social, sino también de la interacción entre medio y cultura, puesto que se plantea a menudo el grave problema de relación entre una geografía física y una geografía humana o poblacional en el propio ámbito de su aplicación a la arqueología, al igual que ocurre con otras disciplinas históricas, antropológicas, sociales, económicas, etc. Este problema se agudiza en el momento de delimitar el exacto significado de la extensión en el tiempo, y en el espacio de cualquier cultura arqueológica, como es el caso cuando la compartimentación del relieve en las tierras sudorientales de Granada, Almería y sudoccidentales de Murcia condiciona pequeños espacios naturales en donde se asentaron numerosos grupos poblacionales, pertenecientes culturalmente a la formación económico-social de Los Millares. En todo este territorio, constatamos de manera resumida y a grandes rasgos tres áreas geográficas principales, la litoral, la depresión prelitorial, y las altiplanicies interiores; subdivididas cada una de ellas en tres subáreas, murciana, almeriense y granadina.

\section{Area Litoral}

Subárea murciana: comprende el Campo de Cartagena y las hoyas de Mazarrón y Aguilas; las tierras de La Vega Baja del Segura, en Alicante caerían fuera del territorio tratado en este trabajo. Subárea almeriense: abarca los llanos aluviales de.Vera o Bajo Almanzora, la vega del río Almería, 
el Campo de Nijar y aledaños, y el Campo de Dalias. Subárea granadina: vegas de Motril y Salobreña.

Toda este área, formada por tierras aluviales, es quizá la que más transformaciones ha sufrido desde el punto de vista geomorfológico a lo largo de los últimos cinco mil años, puesto que la línea de costa ha experimentado diversos fenómenos de colmatación, y por tanto posee menor concentración de asentamientos del periodo cultural de Los Millares.

\section{Area de la depresión prelitoral}

Subárea murciana: se extiende por el valle del Guadalentín-Sangonera-Vega Media del Segura, y comprende principalmente los Campos de Lorca y Totana. Subárea almeriense: incluye el corredor de Sorbas-Turre, el Desierto y el Campo de Tabernas, el valle del Andarax y la Baja Alpujarra. Subárea granadina: la Alta Alpujarra.

\section{Area de altiplanicies interiores}

Subárea murciana: engloba dos zonas, la oriental con las cuencas de Mula, Fortuna, Albarilla y Cieza; la occidental, con las depresiones de Caravaca y Moratalla. Subárea almeriense: ocupa los valles de los ríos Almanzora y Chirivel. Subárea granadina: abarca el Marquesado del Zenete, la Hoya de Guadix, los llanos de Gor-Gorafe, la Hoya de Baza, las altiplanicies de Cullar-Baza y Huescar-Orce, la Vega de Granada, el valle del Lecrín y el Campo de Zafarraya.

Todas estas áreas geográficas y sus unidades morfológicas menores, se hallan conectadas entre si a través de pasos naturales, sea por portillos montañosos y valles-corredores o cuencas hidrográficas.

Al asentamiento de Los Millares se puede acceder desde las tierras nordorientales de Yecla, por los valles de las ramblas de Jumilla y del Judío, hasta Cieza, y a lo largo del cauce del Segura hasta los valles de los ríos Sangonera y Guadalentín, para llegar al Campo de Lorca y proseguir por el corredor de Huercal-Overa hasta el valle del río Almanzora. Remontando dicha cuenca se puede proseguir hacia la Hoya de Baza, aunque también siguiendo aguas abajo se accede a los llanos de Vera, desde donde, a través de valle del río Aguas, se llega al pasillo de Sorbas-Tabernas y desde aquí por la rambla de Tabernas hasta su confluencia con el tramo final del río Andarax, alcanza el yacimiento de Los Millares. Desde aquí a su vez se puede acceder al Campo de Níjar por el río Almería.

También desde Los Millares se puede acceder al Campo de Dalías a través del valle del Andarax en su último tramo, por el valle de la rambla del Cid hasta el río Adra, o por el cauce paralelo del río Grande.

Otro acceso importante proviene de las tierras nordoccidentales de la Hoya de Baza, que une las altiplanicies murcianas por Orce-Vélez Blanco y por el río Corneros al Campo de Lorca; o por el valle de la rambla de Chirivel hasta su confluencia con el río Corneros, o también por los pasos de Baza-Serón, y desde aquí por el valle del río Álmanzora enlazar con los corredores de HuercalOvera o el Campo de Vera.

Otra vía de penetración desde el extremo occidental de las tierras granadinas, que conectaría con el valle del Guadalquivir a través del Guadiana Menor, sería el valle del río Fardes que llevaría directamente a la Hoya de Guadix y por el Marquesado de Zenete y por la Rambla de Fiñana, río Gobernador y río Nacimiento, se accedería al valle del Andarax, o también por el corredor de Gérgal hasta el Desierto y Campo de Tabernas.

El extremo más occidental de acceso relacionado con las tierras jienenses de Alcalá la Real, y también conectado con el alto valle del Guadalquivir, y que comunicaría con la Vega de Granada, 
son los valles de los ríos Luchena, Colomera, o también por el cauce del río Velillas por Moclín y río Frailes hasta el río Genil por Fuente Vaqueros, y desde aquí hasta Iznalloz para alcanzar la Hoya de Guadix. Otro acceso también sería por Padul hasta las Alpujarras y de ahí por el río Guadalfeo acceder hasta Ugijar y alcanzar finalmente el valle del Andarax hacia Los Millares, o al Campo de Dalias por los ríos Grande y Adra (Fig. 1).

Existen por supuesto otras alternativas de penetración natural de menor entidad que no consideramos oportuno exponer con detalle aqui, ya que nos hemos circunscrito a mencionar los accesos principales a nuestro entender. Accesos todos ellos viables, unos más difíciles que otros, a través de cauces fluviales o pasos de montaña, especialmente los referidos a los de Las Alpujarras, cuya alternativa creemos de excesiva dificultad.

Así pues el marco geográfico de cualquier complejo cultural prehistórico cohesionado y uniforme, circunscrito a un concreto medio territorial, tal y como sucede con la Cultura de Los Millares, debe ser tratado y analizado dentro del marco conceptual de la geografía humana, es decir, atendiendo las relaciones existentes entre los procesos sociales y las transformaciones de su medio geográfico inmediato.

Resulta arriesgado circunscribir en unos determinados limites geográficos, la extensión de unos peculiares rasgos materiales de una cultura, puesto que de manera natural sus iniciales límites primarios son rápidamente traspasados en cuanto aquélla adquiere cierta madurez. Por ello cuando se hace referencia a la Cultura de Los Millares se pone en relación por lo general con el territorio del Sudeste peninsular, denominación ésta tradicional en la bibliografía prehistórica española y extranjera consagrada por derecho de uso, aunque geográficamente abarcaría el área, a la vez muy discutible, comprendida desde el extremo oriental de la cordillera Bética y extremo sudoriental de la Meseta hasta el extremo final meridional de los montes celtibéricos, entre los ríos Turia y Júcar (Birot y Solé Sabaris, 1959: 9). En este sentido creemos acertada la opinión del geógrafo Roselló Verger (1968-69: 11), el cual sostiene que la denominación de "sudeste» posee raíces políticoeconómico modernas $\mathrm{y}$, parcialmente connotaciones climáticas, ya que desde el punto de vista estrictamente meteorológico dicha denominación no abarca más que una mínima parte de las provincias de Alicante, Albacete y Almería, y ni siquiera la totalidad de Murcia. Las cordilleras subbéticas vienen a circunscribirlo al estricto dominio litoral, la "región de Alicante-Adra" de Lautensach, la cual posee una extensión total aproximada de $300 \mathrm{~km}$. de longitud y $60 \mathrm{~km}$. de extensión hacia el interior, o sea unos $18.000 \mathrm{~km} .{ }^{2}$, definiéndola como una "franja climáticamente afín que a la vez constituye una unidad geográfica a tener en cuenta» (Lautensach, 1964: 84).

Cualquier actividad humana, individual o colectiva, requiere un espacio físico adecuado para desenvolverse en unas condiciones ambientales propicias a su finalidad esencial, la obtención de un objetivo de subsistencia y desarrollo propios. Dicha actividad siempre se halla profundamente inserta dentro de lo que se ha venido en llamar, la dinámica cultural del grupo social. Ahora bien, definir el concepto de cultura en arqueología prehistórica, además de desbordar el límite de este trabajo, requeriría un mínimo análisis del significado que conlleva dicha idea, y, que por otro lado, ya ha sido tratado por innumerables autores. Sin embargo para nosotros, la cultura no es sino el resultado de la adecuación dialéctica de múltiples interrelaciones, tanto internas como externas, tendente a equilibrar o regular las relaciones establecidas entre una comunidad humana cualquiera y su medio natural inmediato, equilibrio este que a su vez condiciona y resuelve dinámicamente las relaciones propias y mutuas entre los distintos miembros individuales y grupos sociales de la propia comunidad y la de todos ellos con otras formaciones sociales externas, con el fin de regularla a sus propias necesidades de supervivencia colectiva y del control económico, y también a la superación de los condicionamientos naturales del entorno geográfico. Por ello, desde la perspectiva de nuestra definición, rechazamos todas aquellas síntesis y modelos culturales en la arqueología prehistórica basados en un patrón historicista e hiperdifusionista, puesto que dicha visión a nuestro entender unilateral y subjetiva al tratar de manera superdimensionada los factores exógenos como única referencia valorativa de la cultura de un grupo.social determinado, lo único que consigue es 


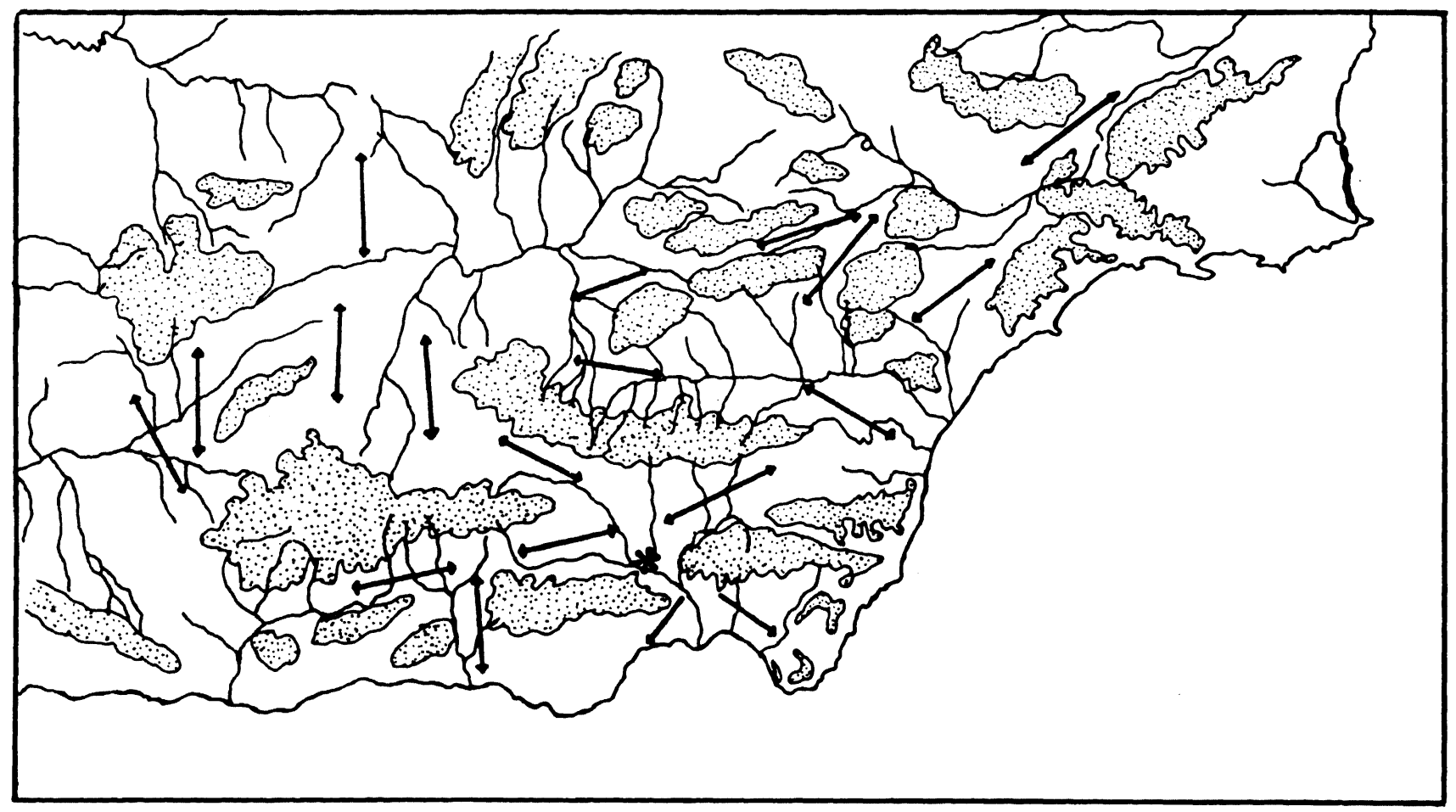

FIG 1.-Principales corredores de paso naturales existentes en Andalucia oriental y Murcia y su relación con el yacimiento de Los Millares.

confundir la infraestructura evolutiva de la propia dinámica interna de una formación social, y también confundir a la vez, la superestructura que conllevan las relaciones de influencias que desarrolla toda formación al establecer de manera lógica contactos con otras culturas más o menos lejanas en el espacio. Las polémicas difusionistas, que hasta hace poco tiempo esterilizaban a nivel conceptual la investigación arquelógica, no tuvieron nunca en cuenta un factor primordial a la hora de valorar cualquier grupo social, como el de la dinámica adaptativa de toda población asentada en un territorio geográfico concreto, e integrándose intrínsecamente con el continuo movimiento en espiral constituido por, acción-respuesta-experiencia-acción.

El grupo cultural de Los Millares no es sino un conjunto de distintos grupos sociales o sociedades estructuralmente desarrolladas, las cuales se destacan a través de dos grandes pautas que conforman unas complejas y diversas colectividades sociales no unitarias, aunque sí altamente análogas, y que se definen por un lado, por la presencia de diversos y numerosos rasgos característicos, o sea, una cultura con unos componentes materiales muy similares y homogéneos, y con unas estructuraciones económicas y sociales basadas en unos semejantes patrones productivos y de necesidades de consumo; por otro lado, mediante unos comportamientos muy similares en las relaciones de producción y explotación de cada uno de los grupos sociales con los entornos inmediatos, y que gracias a ello permitían establecer unas determinadas respuestas adaptativas y muy semejantes en cada uno de los asentamientos de la formación o grupo, aunque no por ello forzosamente idénticas; así pues, podríamos establecer la existencia de una geografía de la formación económico-social de Los Millares, al igual que existe una geografía argárica (Lacasa, 1966; Pareja, 1976; Lull, 1983) y por tanto poder considerarla como un área territorial y cultural (Ferrer Palma, 1980).

Sin embargo, antes de proseguir, no queremos soslayar, siquiera de manera somera y parcial, la crítica a algunas teorias que fueron en su tiempo el paradigma conceptual al definir la Cultura de Los Millares, y cuyo origen proviene de una visión y concepción globales y generalizadoras de 
ciertos modelos teórico-conceptuales procedentes de la antropología historicista y del campo de la paleoetnología.

La influencia de la llamada Escuela Histórico-Cultural de Viena y Marburgo, representada inicialmente por Graebner, Schmidt y Koppers, creó profundas y graves confusiones, no sólo en el ámbito de la prehistoria europea, sino también muy concretamente en la española, durante más de cincuenta años, y que aún todavía permanece anclada en el inconsciente de algunos investigadores actuales. La innegable postura antievolucionista de dicha corriente de pensamiento negaba fundamentalmente la propia capacidad de progreso de cualquier grupo social e infravaloraba la superación cultural generada por sus propios medios, dado que su peculiar concepción etnológica-historicista enfocaba la problemática prehistórica dentro de una falsa perspectiva gnoseológica al concebir la existencia de grandes centros motores primarios, generadores de culturas y civilizaciones que se expandieron a grandes distancias de su lugar de origen mediante una compleja red de mecanismos difusionistas. Representante conspícuo de este paradigma difusionista fue la prehistoriadora italiana Pia Laviosa Zambotti, cuyas teorias rabiosamente difusionistas y monogenistas, representaban la concepción imperante en su época, comprendida desde finales de los años 30 hasta las postrimerías de los 50, y cuyos resultados fueron el fruto de la remodelación de los conceptos metodológicos histórico-culturales de la escuela de Viena, aunque por supuesto pretendiendo presentarlos como un nuevo y superador enfoque de aquélla. Sus teorizaciones sobre la cultura de Almería y de Los Millares hallaron rápidamente eco entre los prehistoriadores españoles de las décadas del 40 al 60 , influidos por la escuela alemana de Kossina y de la arqueología del poblamiento, siedlungsarchàologie, y siendo sus principales representantes los profesores Martín Almagro Basch y Julio Martínez Santa Olalla. Un discípulo de este último, E. del Val Caturla, en 1948 asume un posicionamiento teórico más razonable, menos influenciado por las ideas germanas y más próximo a la ideología difusionista anglosajona del momento y también a la escuela historicista norteamericana. Para este autor, un círculo cultural contiene un concepto de diferencias de tipo etnológico que corresponde a la siempre complicada realidad cultural, pero tales diferencias no se pueden expresar en las distintas áreas geográficas, según él, especie de compartimentos estancos, sino que por el contrario, han de entenderse como diversas gradaciones dentro de un círculo cultural; es decir, una serie de facies de fisonomía diversa, impresas sobre la cultura por las numerosas vicisitudes de los contactos históricos y por la diversidad del medio geográfico. Para dicho investigador, cada rasgo o grupos de rasgos culturales tiene un mecanismo propio y una velocidad de difusión peculiar y distinta de los demás. Así, un nuevo artefacto y/o técnica decorativa serán asimilados con mayor rapidez por un pueblo que, por ejemplo, un sistema social, como el matriarcado, o una nueva idea religiosa, pero también, es muy posible, según él, que un rasgo se transmita aislado; así pues, al pasar de un pueblo a otro, cambia totalmente de función y sentido. Todo ello hace que un área cultural no sea un todo homogéneo y que un rasgo posea una concreta distribución, pero no por ello implica que los demás lo tengan también (De Val Caturla, 1948). Para este autor, la agrupación de unidades sociales dará clasificaciones distintas cuando se opera con un solo elemento nuevo; sin embargo, si simultáneamente se tienen en cuenta todos los rasgos culturales de diversas unidades sociales, se pueden llegar a formar grupos más o menos definidos; ello dará paso a un área cultural, o si se prefiere, una clasificación de grupos sociales que se definirán por sus rasgos culturales. Si se analiza en profundidad el interior de cada agrupación de unidades sociales de una determinada área cultural, se podrá detectar la existencia de unos grupos que poseen una cultura más típica, y cuyos rasgos culturales se presentan de manera más característica; la lejanía geográfica del centro difusor hace disminuir estos rasgos en intensidad. Este centro adquiere entonces el papel de centro primario difusor de rasgos, y conocido como centro cultural o climax. Las zonas geográficas en donde disminuye su fuerza de irradiación, las denomina «zonas de gradación»; en las áreas marginales, los rasgos culturales se entremezclan con los rasgos de la zona vecina, formando entonces culturas híbridas o mixtas, con las características propias de ambas zonas adyacentes (ibídem). También sostiene que un área cultural alcanza su propia madurez a través de un proceso evolutivo histórico, ãunque el paisaje geográfico circundante condicione cualquier cultura establecida en su ámbito. Así 
pues, para dicho prehistoriador, un área cultural es la imagen plana de una determinada cultura, en un concreto momento y en un territorio geográfico homogéneo, y en donde sus elementos materiales poseen un desarrollo histórico, el cual es necesario determinar, de esta manera, el concepto aprendido es esencialmente analítico, basado en datos empíricos y opuesto a las conceptualizaciones téoricas de la escuela histórico cultural, la cual siempre impone limites precisos y determinantes en cualquier cultura específica.

En nuestra opinión, la teorización propuesta por De Val, se inscribe como ya hemos mencionado anteriormente, dentro de la escuela historicista norteamericana fundada por Boas, y continuada por Wissler, el cual influyó en otro gran antropólogo, a su vez representante de la escuela configuracionalista, A. L. Kroeber. La teoria de Wissler se basaba fundamentalmente en la creencia de que una cultura se distribuía por áreas circulares, denominadas wáreas de culturan y originadas a partir de unos centros culturales especificos, reconocibles a través de los rasgos típicos localizables en lugares donde eran más frecuentes. Esta teoría tenía a su favor el establecer de manera rigurosa unos principios de reconstrucción histórica, clasificación de pautas de área y de interpretación de las influencias del hábitat en la expansión cultural (Rossi y O’Higgins, 1980). La escuela de Boas matizaba la teoria de F. Ratzel respecto a que el entorno geográfico determinaba el proceso cultural de los grupos humanos; ya el propio Boas defendía la relación no mecánica entre los grupos sociales y su entorno geográfico próximo, que a su vez lo explicaba indistintamente según sus propias necesidades inmediatas.

Extensa e interminable sería la enumeración de antropólogos y arqueólogos que hasta el presente han valorado la importancia del medio físico y su relación con la cultura de los diversos grupos humanos a lo largo de la prehistoria, y que por necesidades obvias de espacio omitimos; aunque también será conveniente conocer la posición teórica de diversos geógrafos que han considerado al igual que Ratzel, que la geografía humana es por sí misma una antropogeografía, es decir una ciencia de relaciones que se propone investigar la influencia del medio físico sobre los grupos humanos, así como su cultura e historia (Ratzel, 1898, 1899; Gómez Mendoza et alii, 1982). Otros conceptos más fisionomistas de la geografía fueron las también clásicas teorías de Schlüeter, el cual condicionaba ésta como una «morfología del paisaje cultural» y cuyo propósito se centraba en describir e interpretar como geógrafo, la génesis de la fisonomía del paisaje cultural, las transformaciones que ha experimentado a lo largo de la historia, a causa de la actividad conformadora del paisaje que poseen los grupos humanos (Schlüeter, 1906), Hettner a su vez entendía la geografía como una disciplina que atiende principalmente a la ordenación espacial de los elementos o cosas sobre la Tierra; dicha ordenación se ha de escalonar en cuatro ámbitos: continentales, nacionales, regionales, y locales. Define la geografía como una ciencia regional comparativa y a diferencia de Schlüeter, creía que el ser humano es parte integrante esencial del paisaje (Hettner, 1927).

Para nosotros, la Cultura de Los Millares la hemos de incluir dentro del concepto de región o comarca polarizada; entendiendo como región, lo que Puyol Antolín (1975) define como «... la porción más o menos extensa de una superficie que presenta sus rasgos y características comunes»; así pues este concepto puede aplicarse geográficamente con respecto a una cultura arqueológica, en un área en la cual las relaciones entre los centros incluidos en ella son más intensas que las que se reproducen al traspasarlas. Su prefiguración comarcal está en función de la existencia de una intensidad interna de relaciones culturales mayor de la que se produce hacia el exterior, lo cual indica de que se trata de un sistema de funcionamiento unitario. En este caso un paisaje geoeconómico y geo-cultural se presenta como una red de polos entre los que existen corrientes de intercambio (ibídem).

Esta visión geográfica es de capital importancia para el estudio, en este caso, del grupo cultural de Los Millares, puesto que la compartimentación del relieve en las tierras orientales de Granada, Almería y Murcia condiciona pequeños espacios naturales en donde se asentaron numerosos núcleos poblacionales pertenecientes a esta formación socio-económica. Por este motivo, hacemos nuestra la idea referida a que las comarcas geográficas de más valor resultan de las vinculaciones culturales existentes y de las corrientes de intercambio que se producen entre los asentamientos humanos. Sin

\section{T. P., 1991, $\mathrm{n}^{2} 48$}


embargo, las líneas de demarcación de cualquier comarca, sea histórica o prehistórica, siempre resultarán arbitrarias y más aún cuando se trate de establecer límites geográficos y culturales en arqueología. Las áreas culturales casi nunca son simétricas, sus centros no son geométricos y sus límites, generalmente irregulares, dependen de los rasgos de la superficie que afecta la extensión cultural (Hawley, 1962). Una visión distinta es, por ejemplo, la de Wissler, para quien un área cultural es una sucesión de zonas de distribución que rodean un núcleo, el cual actúa a su vez como un punto de dispersión, y que a partir del mismo se difunden los rasgos y los complejos culturales; también sostiene que el concepto de área cultural se basa en la localización de la cultura en "segmentos de terreno" y no en una distribución aleatoria debida al azar (Wissler, 1927).

Para nosotros, al igual que sostenía Hall, sería enormemente valioso aproximarse a una región a través de la cultura, en lugar de hacerlo por medio de su propia configuración fisionómica, según la visión clásica (Hall, 1935). Las áreas culturales se subdividen a su vez en otras menores, subáreas, las cuales presentan variaciones dentro de las unidades principales. Existe por general, una estrecha relación entre las culturas de una determinada área y los factores fisiogeográficos, así como también con su cobertura vegetal y forestal, si bien por supuesto se pueden apreciar importantes diferencias de grado entre estas relaciones. Sin duda, existe una clara tendencia en la actividad humana que se trasluce en su estructura cultural interna, a modificar las características físicas del área en donde habita. Ello es una consecuencia lógica, por cuanto el ser humano vive en estrecha asociación con su entorno inmediato y se halla comprometido en la interrelación de sus actividades con su ecosistema próximo; sin embargo, ésto no significa que el medio físico limite y determine fundamentalmente la actividad cultural del grupo social humano, por el contrario éste modifica el paisaje en función de sus pautas productivas.

Todas estas consideraciones sobre la incidencia del marco geográfico en el desarrollo de las culturas quedan notablemente clarificadas en la concepción ecológico-cultural que Vidal de la Blache confiere a la Geografía. El objeto de su estudio, se basa en el enfrentamiento de los grupos humanos con el medio natural que los envuelve. El interés de este autor se centra especialmente en la Tierra como morada del ser humano, y los modos de vida que se desarrollan en ella, resultado de la relación del Hombre con la Naturaleza. Los tres componentes, medio, hombre y modos de vida, son la base conceptual de la geografía ecológico-cultural que sostenía Vidal de la Blache, contrastando fuertemente con las propuestas alemanas de principios de siglo, en las cuales el paisaje o fisionomía prevalecen sobre cualquier problemática. Para el geógrafo francés sin embargo, son «los modos de vida" que se han desarrollado en un área cualquiera, los que adquieren mayor relevancia. Por su parte, la escuela alemana de esta época considera el medio natural como un marco sin causalidad ninguna, ni tampoco valora la acción antrópica como un factor de modificación del espacio; así pues, es definido como un elemento territorial no social. Sin embargo, la geografía vidaliana, conserva su corte clásico, puesto que a pesar de considerar a los grupos humanos como agentes dinamizadores, se enfrenta a la ardua tarea de explicar las conexiones significativas entre hombre y medio en un contexto temporal histórico. La contradicción de la geografía humana vidaliana, a pesar de todo, no es tan grave cuando ésta trata de conexiones mucho más estrechas entre hombre y medio, como ocurre para las etapas prehistóricas (Vidal de la Blache, 1911). Para algunos geógrafos del ancien règime, la dificultad primordial de la geografía estribaba en la incorporación del ser humano dentro de su propio esquema teórico, sin sobrepasar las fronteras propias de esta ciencia. Busch-Zanter (1937) considera esencial el papel del factor humano como elemento que permite la estructuración del paisaje, y establece dos objetivos principales: uno, mediante la valoración de la investigación empírica y las relaciones establecidas entre HombreNaturaleza; otro, vendría dado por determinar las conexiones entre Sociedad-Espacio. Así pues, el espacio no es solamente el marco físico, en tanto que el grupo social queda diferenciado en base a la división social del trabajo; por ello, la sociedad es valorada como sujeto y objeto a la vez de la geografía, o sea se remite a la sociología a fin de estudiar la organización espacial de la sociedad. Bobek, posteriormente con un criterio más tradicional, ligado a la escuela francesa vidaliana, propone el estudio del género de vida en los grupos sociales como clave para analizar la organización 
del espacio. A nosotros nos interesa resaltar uno de los aspectos más problemáticos en la geografía social paisajística de este geógrafo austríaco, cuando renuncia al análisis sistemático de causas económicas, politicas y psico-sociales, para la formación de los grupos sociales, ya que sólo tienen valor para dicho investigador en tanto motivaciones espaciales. Bobek establece una geografía social funcional, a fin de superar las dificultades del estudio del paisaje cultural, ya que la organización espacial de un área puede estar mediatizada por agentes sociales muy distantes (Bobek, 1948).

Los intentos de Harvey (1969) y Hard (1973) de compaginar el funcionalismo en geografía, aún a pesar de partir de posiciones autocriticas, no han supuesto una solución a la dificultad de entroncar los presupuestos de la geografía tradicional de la acción social en la modificación del paisaje (paisaje cultural) y la organización espacial de los grupos sociales que desde la lejanía transforman el medio. Otro autor, Hartke (1959) aboga por el abandono del concepto paisaje como tema principal de los estudios geográficos, ya que sólo pretende deducir procesos sociales con significación espacial únicamente a través de la comprensión del paisaje, ya que éste es tan solo un campo de observación. Para este investigador, los indicadores del paisaje son los que explicarían los procesos sociales que modificaron el espacio.

Asi pues, la pretensión de los geógrafos sociales funcionalistas, es explicar el comportamiento de los grupos sociales con significación espacial y con este fin uutilizarn el paisaje, pero sin interpretarlo. Hartke concibe el grupo social no sólo vinculado a un territorio concreto, sino como una «institución que genera valores" y en este sentido se plantea la existencia de una "coacción originada por un grupo", el cual provoca un comportamiento homogéneo sobre el espacio por parte de todos los individuos que constituyen el grupo social. Hartke modifica radicalmente el concepto de grupo social propuesto por Bobek, -para quien el grupo socio-económico determina el propio comportamiento del individuo-, puesto que no se trata solamente de un conjunto de individuos con comportamientos similares, sino de la respuesta de comportamientos homogéneos en el espacio, explicados por una situación económica. Así, el grupo social se concibe como una institución que produce valores.

Podemos señalar que en la década de los años 50, junto con la llamada "revolución cuantitativa" que más adelante trataremos, se inicia una nueva visión en la geografía social, basada en la determinación de espacios sociales, caracterizados por un comportamiento homogéneo de los grupos sociales. Esta elaboración de una geografía social paisajística que intenta estudiar la estructura interna de la acción social, a través de lo concreto del paisaje, no sólo se aplicó en Alemania, sino también alcanzó difusión amplia en los países anglosajones y en Francia. Ya unos años antes en este último país, destacó Demangeon (1942) el cual subraya en sus trabajos, el protagonismo que la historia tiene para comprender el paisaje cultural, ya que las condiciones del paisaje actual no son causales y puede ser comprendido a través del conocimiento del pasado. Rechaza este autor el estudio de las relaciones entre hombre y medio físico y también el estudio de las relaciones entre grupos sociales y medio, basándose en la insuficiencia, ya sea por defecto, -el hombre determinado por el medio-, o por exceso, - grupo social determinado por el medio-, propone por tanto definir la geografía humana como el estudio de las agrupaciones sociales en su medio geográfico. Para ello, sustituye el concepto kmedio físicon por el de "medio geográfico", y destaca la capacidad modificadora en el medio. En definitiva, para A. Demangeon no se alteran demasiado las pautas tradicionales de la geografía, pero sí se delimitan sus competencias de estudio; a la vez que la geografía humana es definida sin ambajes como la ciencia que se ocupa del estudio de la vinculación territorial de los grupos humanos. A un mismo tiempo en los Estados Unidos, a fines de la década de los años 50, aparece un grupo de geógrafos que desarrollan y revisan nuevas técnicas y métodos geográficos basados en la aplicación de métodos estadísticos y programas informáticos, con el fin de modernizar los viejos conceptos de esta disciplina, mediante la llamada "revolución cuantitativa", base de la New Geography. Fueron tres los nuevos conceptos aplicados, entre otros, la llamada teoría de la localización, location theory, cuyos presupuestos provienen del campo teórico de la Escuela EcológicoCultural de Chicago; la llamada teoría de los lugares centrales, central place theory aplicada por W. Christaller y otros nuevos geógrafos, tales como Lösch (1954) y la teoría de la difusión, diffusion

\section{T. P., 1991, $\mathrm{n}^{0} 48$}


theory, por la cual las innovaciones se extienden en el espacio y el tiempo en un sistema social. Otras aplicaciones se realizaron mediante el análisis del área social, social area analysis, y también en la geografía del comportamiento, behavioural analysis geography.

En la "revolución cuantitativa", los investigadores se interesaron en la organización espacial de la sociedad, el movimiento de influencias culturales, comerciales y poblacionales, y por supuesto en el comportamiento espacial del hombre, la estructura espacial y la interacción espacial entre otros. En definitiva, la geografía cuantitativa se apropia del concepto de espacio como un elemento cuantificable y pretende renovar la metodología y teoría geográficas a un nivel científico nuevo y superior. Esta tendencia perduró hasta fines de los años 60, y fue fuertemente contestada al final por sus propios creadores.

En los años 60, la posición de la geografía social dentro de la geografía humana, se debate entre ser una sociogeografía o geografía sociológica, - cuya finalidad sería el análisis de las estructuras y relaciones sociales en un terreno concreto-, o bien como una sociología geográfica más interesada en el estudio de la distribución espacial de los fenómenos sociales. Junto a estas tendencias, se mantienen los conceptos tradicionales y la interpretación marxista como en el caso de P. George (1966) que intenta comprender la geografía humana, explicando los fenómenos sociales a través de los hechos económicos. Para otro geógrafo francés, como Gourou (1973), los elementos de la acción humana en los paisajes naturales no tienen sentido alguno, sino es a través de las civilizaciones como medio humano, y de las propias condiciones físicas del medio natural. Esta acción es el paisaje humano, que a su vez viene determinada por las técnicas que se hayan aplicado para su explotación; por otra parte, los elementos físicos y los elementos humanos del paisaje total no constituyen un conjunto o sistema estructurado; no es tampoco por otra parte, una ecología geográfica ni humana, ya que el hombre casi siempre ha pretendido dominar y explotar el medio físico, el cual por sí mismo no tiene sentido sino únicamente a través de las civilizaciones que lo transforman. El paisaje no es un ecosistema equilibrado, sino un producto de las tranformaciones realizadas por la propia acción humana en el medio físico y que según dicho autor, ya desde el Neolítico el medio ha dejado de poseer un equilibrio natural. Por otra parte, para Rochefort (1963) la geografía social ha de interpretarse como una geografía del comportamiento.

En la década de los 70, la geografía humana sin embargo, empieza a abandonar en cierta medida la influencia proveniente del campo de las ciencias sociales. La escuela de Munich recoge los postulados tradicionales de la geografía humana, -o sea entendiendo el concepto de paisaje como punto de partida-, y dirige su investigación a explicar los movimientos o cambios profundos en las estructuras espaciales existentes (Rupper y Schaeffer, 1979). Se trataba pues de orientar el estudio de las formas de la organización espacial de la sociedad, a las que se explica como el resultado de la interacción entre los grupos humanos, al realizar sus funciones vitales; entonces el paisaje se entiende como uun campo de procesos, a partir del cual y con la actividad de los grupos humanos, ...se regeneran, cristalizan o modifican muchas estructuras» (ibidem, 1979: 17). Para estos autores, el paisaje cultural es dinámico, como la imagen de las funciones vitales de una sociedad en un territorio dado. La organización espacial de la sociedad será el resultado de la interacción de los distintos grupos sociales que la componen al realizar las funciones básicas. Así pues, la geografía social es definida como una geografía de los grupos humanos. Los supuestos de esta geografía serían los siguientes: a) el paisaje cultural no es estático sino dinámico, reflejo de las complejas funciones vitales de una sociedad en un área o territorio; b) la organización espacial se explica como resultado de la interacción entre los grupos sociales distintos que la componen al realizar las mencionadas funciones vitales básicas; c) la geografía social es definida como la geografía de los grupos humanos, los cuales han de ser distintos aquí al concepto que se utiliza en sociología, y considerarlos como los principales responsables de los comportamientos espaciales homogéneos. Los postulados de la escuela muniquesa fueron objeto de numerosas críticas. Uno de los principales opositores fue Wirth (1981), quien resaltó la paradoja de estos planteamientos, ya que por un lado se presentan como un saber científico-social inserto en la tradicional antropogeografía clásica, pero introduciéndose a la vez conceptos tales como función, grupo y sociedad. En definitiva, se pretendía 
proporcionar un cuerpo teórico basado en la organización espacial de la sociedad y personalizar de nuevo la geografía como una ciencia con carácter propio.

Por su parte, la geografía norteamericana se consideraba fundamentalmente como una ciencia relacional, ya que ciertos círculos de investigadores trataban de estudiar el medio y el hombre, pero para otros geógrafos lo más importante a tener en cuenta eran las relaciones existentes entre el medio y la historia, ya que el medio geográfico objetivizado por factores climáticos, botánicos, hidrológicos, pedológicos, locacionales, etc., sin lugar a dudas influenciarian directa o indirectamente a los grupos humanos, y por tanto a su cultura. Estas influencias, a su vez, crearían unas respuestas humanas de tipo económico-social y de cultura material, entre otras. El hombre, pues, se adapta al medio que lo rodea de una manera determinista, aunque posteriormente esta idea se modificará, resaltándose el papel activo y transformador del hombre frente al medio. Este giro, valorando el factor humano en la geografía, lo dará Barrows (1923), así como la utilización de los principios de la ecología como concepto organizador. En estos mismos años, Saver (1927) define la geografía como una ciencia-objeto contra la conceptualización científico-relacional y pretendiendo convertirla en un estudio de la morfología del paisaje cultural, o sea una geografía histórica, interesada por la génesis e interpretación del paisaje natural y cultural, teniendo siempre en cuenta el papel activo del ser humano. Así pues, la visión de Saver adjudica al hombre el papel de transformador principal de la propia morfología del paisaje y también como organizador del espacio geográfico, con lo cual el paisaje cultural será el resultado de la ocupación humana; a dicha ocupación humana del paisaje, la geografía norteamericana dedicará su investigación estudiando de qué manera los grupos humanos han incidido en el espacio físico. Así, la geografía se aproxima al estudio de la cultura, si bien en un principio se atiende únicamente a los conceptos materiales de cultura para, posteriormente a través de la colaboración con otras disciplinas, entenderla como cultura antropológica. Esta incorporación social de la geografía, ya llegó a planteársela Le Play en el siglo pasado, al igual que Ratzel, influyendo estos autores, no sólo en el mundo de la sociología, sino también en el de la antropología. Le Play creó una unidad social de investigación empírica basada en un modelo primario social, la familia, con unos modos de trabajo adecuados al lugar o al espacio ocupado (Le Play, 1877-1879).

En otro orden de cosas, existen diversas polarizaciones de objetivos, también llamadas tradiciones de estudio en el amplio marco de la geografía; sin embargo, nosotros adoptaremos aquí el propuesto por H. Capel (1983), ya que creemos que este autor es quien mejor amplía las posibilidades y objetivos de la actividad geográfica, y que según él abarca los conceptos físico, corológico, paisajístico, ecológico, espacial y social. Uno de los problemas clave de la geografía que más nos interesa directamente por su influencia en el campo de la prehistoria y la arqueología es el nexo que se establece entre el hombre y el medio, y como muy bien escribe Capel, «... particularmente los ajustes del hombre a las condiciones cambiantes del medio natural, así como la repercusión de las acciones humanas sobre este medio..." (Capel, 1983: 6). Por tanto, nos han de interesar directamente los avances de los geógrafos en los dominios de la tradición ecológica, paisajística, espacial y social. Siguiendo a Capel, definiremos la tradición ecológica en geografía, como el estudio de los efectos espaciales del ambiente natural en el hombre; o también los ajustes de los grupos humanos al medio físico; a la vez como las relaciones entre el hombre y el medio geográfico. Como ecología humana: también, en calidad de relaciones y reciprocidad en el ecosistema terrestre; o igualmente a modo de sistema hombre-naturaleza; o de igual modo que una interdependencia e interacción de fenómenos heterogéneos físico-humanos; o finalmente, como los complejos de interacciones en la superficie terrestre. La tradición paisajística nos afecta directamente en el estudio del paisaje como complejo natural y como paisaje cultural y humano. A su vez la tradición espacial abarca no sólo la localización y distribución de fenómenos en la superficie terrestre, sino también el estudio del espacio y las relaciones espaciales, así como la organización de las mismas. Finalmente, la tradición social, investiga las sociedades humanas en su distribución espacial, a la vez que la cultura y los ajustes del hombre a la naturaleza y las sociedades humanas como grupos espaciales (Capel, 1983: 10).

Así, la creencia de Hartshorne de que la geografía puede ser una definición e interpretación de 
la Tierra como el mundo del Hombre, nos obliga a acercarnos a la problemática de la geografía humana, y de hecho nos ayuda a los arqueólogos, no sólo en los estudios de campo, sino también en la orientación de la metodología teórica de nuestra disciplina, ejemplo de ello es la incorporación en estos últimos años de conceptos tales como la teoría de los lugares centrales de Christaller, los análisis locacionales, entre ellos los espaciales, territoriales y límites o fronteras, etc., todos ellos préstamos de la geografía que han abierto nuevas posibilidades de investigación y análisis en las diversas especialidades de la Arqueología; incluso los estudios geomorfológicos, ligados a la tradición física, se integran en las investigaciones puntuales de los yacimientos arqueológicos. Gracias a estas aportaciones, hemos asistido en estos últimos años a la aparición de una especialidad que aunque todavía se halla en sus inicios, augura un brillante futuro, la Arqueología Espacial.

Aún a pesar de las numerosas reticencias, no sólo de muchos geógrafos, sino también de algunos arqueólogos, la geografía humana cada vez más habrá de estrechar sus lazos con otras ciencias afines en sus objetivos últimos, espacio, tiempo y hombre, como son la Arqueología y la Historia. De hecho los modelos utilizados en la arqueología espacial, sirven de referencia a los análisis locacionales en arqueología (Johnson, 1972; Clarke, 1977; Hodder y Orton, 1976, entre otros). No sería desdeñable que, en el ámbito de la geografía humana, apareciese una especialidad afín, la paleogeografía o arqueogeografía, la cual tuviese en cuenta la evolución de los paisajes y su interacción con los grupos humanos a lo largo del tiempo, lo cual conjuntamente con la geoarqueología, abarcaría el complejo proceso del hombre, su hábitat territorial y su medio natural en el pasado. Esta especialidad debería integrarse dentro de la llamada geografía histórica, reconocida como comisión en la Unión Geográfica Internacional, y que a pesar de poseer cierto arraigo en Gran Bretaña, Alemania, Estados Unidos, Canadá y en menor grado en Francia, -especialmente dedicada al estudio de los paisajes rurales y sus estructuras agrarias-, no goza de excesiva popularidad entre la mayor parte de los geógrafos, aunque algunos de ellos han contribuido positivamente en su desarrollo (Baker, 1952 y 1972; Butling, 1966; French, 1968; Clark, 1954; Harris, 1967; Planhol, 1968).

Frente a la concepción tradicional vidaliana de la geografía como "ciencia de los lugares no ciencia de los hombres", contraponemos la superación de este concepto a través de la definición de Brodel, la geografía como estudio espacial de la sociedad, o el estudio de la sociedad en el espacio. En Alemania se efectúan estudios de la evolución histórica del medio rural, paisajes rurales y estructuras agrarias; en Inglaterra, la Escuela de Cambridge incide en la geografía rural e histórica; en los países escandinavos han podido llegar a la síntesis entre ambas disciplinas, geografía y arqueología y/o historia; y más modestamente en América del Norte, la Universidad de Wisconsin investiga en la línea de la geografía histórica, y la Universidad californiana de Berckley incide en la etnohistoria y en los estudios de poblamiento, así como su evolución.

Por su parte, la tradición física en geografía viene representada por un fuerte componente naturalista y positivista, basados en un monísmo metodológico, entendido como unidad de la ciencia y del método científico, todo lo cual viene caracterizado por un reduccionismo y racionalismo científicos y por la aplicación de métodos de tipo predictivo y empirista, basados en la nomotética y en un concepto ahistórico de la ciencia, dando prioridad al establecimiento de teorías. Los fenómenos son analizados desde un punto de vista geomorfológico descriptivista y evolucionista. Su mejor representante de principios de este siglo puede ser Davis (1912), gracias a su teoría de los ciclos de erosión, junto con Richthofen (1883). En Francia debido al magisterio de Vidal de la Blache, se reacciona ante esta fuerte tendencia empirista, mediante estudios geomorfológicos regionales historicistas; en Inglaterra apareció una fuerte reacción contra las tesis de Davis, también bajo una perspectiva regional paisajística, gracias a las investigaciones de los denominados geomorfólogos o geólogos; en Alemania, también se inició una fuerte crítica a los ciclos de erosión, destacándose entre otros, Hettner (1927), adscrito a la escuela historicista, la cual subraya el desarrollo histórico que afirma la personalidad de las ciencias humanas y contrapone Naturaleza-Historia, además afirma la imposibilidad de la predicción de leyes en las Ciencias Humanas y utiliza el método inductivo y niega el valor de las teorizaciones previas. A partir de los años 20 y 30, la reacción contra las hipótesis de Davis dio paso a una orientación en la geografía física, especialmente en

$$
\text { T. } P ., 1991, \mathrm{n}^{2} 48
$$


geomorfología, climatología e hidrología, del tipo empirico-historicista, especialmente en temas de investigación puntuales y regionales, perdurando hasta la década de los 60 , momento de la aparición en Estados Unidos y Gran Bretaña de la llamada "Nueva Geografia", y en donde se imponen unos criterios de investigación en la cuantificación (estadística, matemática y topología) y desarrollo de las teorías generales de los sistemas y modelos, aplicados a una microescala, y también al estudio de las geometrías superficiales, como por ejemplo los análisis de mallas, al igual que sucedía en el campo de la geografía humana. Estos análisis han de ser aplicados en sus concretos y específicos contextos, ya que "un modelo físico no es una ley de la naturaleza" (Rosenfeld, 1972: 98); a la vez, muchos autores, se posicionaron dentro de un contexto de pensamiento inspirado en el racionalismo critico de Popper.

Posteriormente a finales de la década de los 70, aparece tanto en el campo de la geografía física como en el de la humana una fuerte oposición a los trabajos basados en la investigación topológica sobre redes y a los modelos cuantitativos "funcionalistas" (Thorres, 1978: 16), ganando posiciones los enfoques basados en la comprensión de las relaciones del medio físico natural con los grupos sociales y el comportamiento de los mismos, valorando los problemas teóricos junto con una reflexión epistemológica.

En la década de los 80, la Geografía intenta desarrollar concepciones desde la perspectiva neopositivista para solucionar problemas de organización espacial de la sociedad, a la vez que pretende relacionarse con otras disciplinas sociales, abandonando así la concepción historicista en la búsqueda de métodos aplicables válidos para establecer una geografía social, tratada como una ciencia aplicada, mediante teorías y métodos científicos sociales.

En el campo de la arqueología prehistórica, la influencia del funcionalismo geográfico ha conducido a la investigación o explicación de paisajes culturales complejos, desde la perspectiva de una arqueología sociológica, basada en el estudio de las relaciones y la diferenciación de los campos de la vida humana en cada uno de los distintos períodos prehistóricos, siempre bajo el prisma del ordenamiento espacial, y a unas conexiones económicas referidas a través de ideas valorativas previas, todo ello dirigido a crear modelos de influencia espacial (Chorley y Hagget, 1967; Berry y Pred, 1961; Hagget, 1965; Everson y FitzGerald, 1969; Bunge, 1962; Clarke, 1977; Hodder y Orton, 1976) lo que ha conllevado a la aparición de una especialidad nueva, la arqueología espacial o arqueología geográfica, e incluso a una ecoarqueología (Butzer, 1971 y 1982; Binford, 1977; Bailey, 1983; Redman, 1978; Sahlins, 1974). El propio Butzer (1982: 11) reconoce que la arqueología «... ha dependido así mismo de la geología, la biología y la geografía..." dentro de lo que él denomina enfoque contextual. Esta arqueología geográfica no pretende sino establecer en cierto modo una paleogeografía que ha de interesar, no sólo a los propios geógrafos y prehistoriadores, sino también a ecólogos culturales, geógrafos sociales o geógrafos historiadores, e incluso contribuye al estudio de la geomorfología, la paleobotánica y a la paleozoología.

La base teórica de la llamada arqueología espacial ha adoptado conceptos analíticos provenientes del campo geográfico de ambiente macroespacial, e incluso de las teorizaciones de la llamada ecologia medioambiental, como pueden ser los modelos de gravedad (Morril y Dormitzer, 1979), las áreas de influencia, como el modelo de Von Thünen (1966), la teoría del lugar central (Johnson, 1972), los territorios de explotación (Higgs y Vita Finzi, 1972) y los de captación (Davidson, 1983), entre otros diversos estudios y aplicaciones.

Finalmente, podemos señalar que la investigación arqueológica española a partir de finales de los años 70 y a lo largo de la década de los 80 ha incorporado positivamente en nuestra opinión, algunos conceptos de la geografía humana, y muy especialmente la procedente del campo de la "revolución cuantitativa" (Burillo, 1979 y 1982; Burillo y Peña, 1984a y 1984b; Cerrillo y Fernández, 1980; Fernández Martínez y Ruiz Zapatero, 1984; Rodríguez Blanco, 1977; Ruiz y Molinos, 1984; S.A.E.T.-C.U.T., 1984, 1986 y 1989), aunque también ha heredado todas las polémicas y contradicciones de los propios geógrafos, aplicándolos a la metodología propia, igualmente preñada de discusiones y aplicaciones muchas veces mecanicistas y reduccionistas de modelos epistemológicos a menudo ajenos, provenientes de la geografía, antropología, etnografía, sociología, etc., del mundo anglosajón 
principalmente. Así pues, el panorama actual de nuestra arqueología se encuentra saturado de múltiples aplicaciones $\mathrm{y}$ análisis cuya dinámica parece conducir a una situación gnoseológica compleja y a unos forzados intentos para establecer teorias, modelos e hipótesis. Una pléyade de entusiastas seguidores de investigadores y pensadores de la talla de Clark, Binford, Chang, Hodder, Higgs, Hempel, Popper, Kuhn, Harris, Godelier, Althusser, irrumpen en la escena de la investigación arqueológica española, todo lo cual configura que el panorama actual sea muchas veces confuso, variopinto y anárquico, y en donde conviven, no siempre con el debido respeto mutuo, arqueólogos tradicionales, "new», "neos", "post», radicales, escéptico-sincréticos, eclécticos, marxistas, marginales, "mortuorios" y patrimonialistas oficialistas; complejo panorama que conlleva una crisis de hiperdinamismo teorético-conceptual, fenómeno muy semejante a lo ocurrido en el campo de la geografía, cuyos lazos con nuestra disciplina en muchos aspectos, hemos pretendido esbozar en este trabajo. No sabemos si algunos de los arqueólogos y geógrafos sociales estarán de acuerdo con nosotros respecto a la afinidad en ciertos aspectos entre nuestras disciplinas, pero, si, nosotros al menos, estamos de acuerdo con algunos de ellos.

Con los escasos datos paleobotánicos provenientes de los análisis polínicos y antracológicos que actualmente se poseen de los yacimientos pertenecientes al ámbito cultural de la formación económico-social de Los Millares, se hace muy difícil por el momento la comprensión del medio natural y climatológico de este vasto territorio que se extiende desde las altas tierras de Montefrío, en el extremo occidental de Granada, hasta los llanos murcianos del Campo de Cartagena, en el extremo oriental del Sur peninsular, y que constituye a nuestro parecer el territorio geográfico correspondiente a la mencionada formación. Unicamente los análisis faunísticos nos proporcionan un indicativo muy genérico de la cobertura forestal y del medio geográfico en que pudo desarrollarse el área cultural que describimos y que geográficamente abarca diversos ecosistemas distintos aunque interrelacionados; si bien las conclusiones provenientes de los análisis realizados deberán ser contrastados y sintetizados con prudencia, a fin de no caer en errores interpretativos en las reconstrucciones paleoambientales (Morales, 1990: 268).

A finales del período Atlántico y comienzos del Subboreal, las condiciones climáticas de todas estas tierras, creemos no eran semejantes a las imperantes actualmente, tal y como Kubiena, Lautensach, Thornes, Gilman, Schüle y Walkers, entre otros, han pretendido establecer. En nuestra opinión, el medio subdesértico de la mayor parte del territorio en cuestión, no es sino una consecuencia histórica que la acción antropogénica a lo largo de cinco milenios ha ido estableciendo y fomentando parcialmente mediante la tala de bosques y deforestación gradual provocada por el uso y abuso de la ganadería y agricultura extensivas, y también por la acción degenerativa de las alternancias o períodos cíclicos puntuales de humedad-sequedad en dichos territorios, y de los que nada sabemos con certeza por falta de estudios concretos de los mismos, aunque no dudamos existieron fluctuaciones de mayor o menor incidencia a lo largo del III milenio. Así pues, creemos ha existido un largo proceso degradativo de desecación climática y de una progresiva e irreversible deteriorización generalizada en todo el territorio. Hemos de tener en cuenta además la dinámica atmosférica peculiar y compleja de la climatología del Mediterráneo occidental que se presenta como una cubeta de elevados rebordes y que, en conjunto y por lo general, tiende a remansar una masa de aire cálido y húmedo; por tanto no es de extrañar que la incidencia humana en el medio geográfico conllevase a situaciones degenerativas en la interrelación clima-paisaje, acelerada en progresión geométrica, muy especialmente a partir del siglo XVI hasta llegar al máximo de explotación forestal, a causa de los intensos trabajos de minería, llevados a cabo a partir de la segunda mitad del siglo XIX. La erosión de los suelos en las tierras de Granada, Almería, Murcia y Alicante, por falta de una adecuada cobertura vegetal, ha ocasionado gravísimos fenómenos erosivos, así se ha podido constatar actualmente que en estas provincias, «... en terrenos con cultivo de vid y almendros, una pérdida de suelo de algo más de $500 \mathrm{Tn}$. por hectárea con lluvias intensas de 60 litros por metro cuadrado y hora. Conviene hacer la observación de que estas intensidades son elevadas pero en absoluto excepcionales; sobre todo en los aguaceros otoñales procedentes de 
nubes tormentosas, máxime si éstas han sido generaḍas bajo situaciones de "gota fría" (Toharia, 1988: 64).

Por otro lado, los factores geográficos respectivos de este territorio, no sólo de la Andalucía oriental, sino también del mal llamado sudeste, han facilitado la alteración de los suelos, especialmente por la disposición topográfica y gradual descenso de las altas sierras del interior hasta los llanos costeros, todo lo cual, además, ha determinado una cierta regularidad de gradientes térmicos y pluviométricos, aunque parcialmente alterada por la existencia de cubetas y depresiones rodeadas por rebordes u orlas montañosas pre y litorales, proporcionando unos valores de temperatura, pluviosidad y humedad, así como de otros factores dinámicos, como el régimen de vientos, por lo que todo ello determina fenómenos meteorológicos importantes, tales como inversiones térmicas o "gotas frías", cuyo efecto altera sin lugar a dudas, la unidad climática local de las zonas geográficas. Así la formación de ciclogénesis en la cuenca occidental mediterránea y muy especialmente en las regiones orientales meridionales y del sudeste peninsulares no es un hecho aislado, ya que las depresiones que se originan en un $70 \%$ en dichas áreas provienen del Mediterráneo oriental por causa de las corrientes de aire canalizado a través del golfo de Sirtes; así cuando se establece un anticiclón en la península de los Balcanes existen fuertes precipitaciones en el sudeste y levante de la Península Ibérica. Todo ello influye en la pluviometría regional sudoriental de Andalucía y Murcia.

Ahora bien, aunque debieron existir variados microclimas locales en las distintas zonas geográficas y altimétricas en el territorio de Los Millares, creemos que hubo durante el III milenio un denominador común climático, mayor humedad relativa. Escasos son todavía los testimonios que pueden avalar nuestra afirmación, pero la obtención de valiosos datos faunísticos y paleobotánicos en unos pocos yacimientos en distintas áreas geográficas del sur peninsular, nos proporcionan una cierta uniformidad en las hipotéticas reconstrucciones medioambientales del período calcolítico.

En el extremo occidental del área interior montañosa granadina, concretamente en la zona de la sierra de Parapanda, el asentamiento de Los Castillejos de Montefrío, en su fase calcolítica, denota la presencia, gracias a los restos de la fauna estudiada, de un bosque mixto, -actualmente en algunos puntos de las sierras existen todavía bosques relictos de encinares y carrascales-, y también a la vez existieron amplias zonas de pastizales (Uerpman, 1979).

En la misma área, aunque en la zona nordoccidental, en los altiplanos de Baza, Huescar y Orce, en el yacimiento de El Cerro de la Virgen de Orce, la reconstrucción paleoambiental parece indicar la existencia de tres zonas diferenciadas: la serrana, donde pudo existir un bosque mixto extenso; las altiplanicies, en las que crecerían grandes extensiones de pastizales y bosques abiertos; las tierras bajas, próximas a los valles fluviales, en donde pudo desarrollarse un bosque de galería (von Den Driesch, 1973).

En el área de la Depresión interior almeriense, en las zonas del Desierto de Tabernas y del bajo valle del río Andarax, el estudio arqueozoológico de Terrera Ventura y la presencia de determinada fauna de Los Millares y de Almizaraque han establecido con cierta seguridad la existencia de bosques de ribera, tipo fresnedas, en las zonas de penillanuras fluviales; aunque en los altiplanos y sierras de baja altitud, 200/600 m., parece que pudieron existir bosques de tipo esclerófilo mediterráneo abierto y regresivo, quizás formado por encinares o carrascales con especies heliófilas -asociación de encina litoral con carrasca-, Olea europaea o acebuche, garriga poco densa, -Quercetum cocciferae collunetosum-, estepa, -Cistion mediomediterraneum-, maquia provenzal de acebuche, prados sabanoides de herbazal pajizo, - Hyparrhenia hirta-, esparto borde, - Lygeum spartum - y pastizales en zonas de vegetación nitroheliófila; en la zona de montaña media, 400/1600 m. de los territorios pre y litoral, pudo convivir un bosque perennifolio submediterráneo, típico de montaña baja-media, junto con pequeños bosques de caducifolios en las zonas de umbría, y bosque esclerófilo mediterráneo septentrional, además de encinares en regresión junto con especies heliófilas, -asociación de encina litoral con carrasca-, maleza de estepa montañosa, -Cistion laurifolii-, y brezales, todo extendido en las vertientes de solana; también abundaría el sotobosque en terrenos 
de piedemonte, en las zonas de montaña medias-alta, 800/1800 m., crecerían áreas importantes de bosques de coniferas.

Las áreas próximas a los yacimientos de Terrera Ventura y Los Millares parece pues que tuvieron un ambiente de mayor humedad y una más extensa cobertura vegetal en las sierras próximas y llanos circundantes con la presencia de bosques mixtos abiertos y áreas de pastizal.

En la zona del área litoral, el yacimiento de Almizaraque se encontraba próximo a bosques de pino carrasco, -Pinus halepensis-, y bojedales, -Buxus sempervivens-, los cuales crecerían en las sierras de Almagro, Almagrera y Los Pinos.

En el extremo nordoriental del territorio, en la zona de los altiplanos murcianos, el yacimiento de El Prado de Jumilla presenta también una cobertura de Pinus halepensis, además de la presencia de oleáceas, Buxus sempervivens, Pistacea lentiscus, o lentisco, cupresáceas, Ulmus minor, u olmo, Populus alba, o álamo; en cuanto a la cobertura herbácea se ha detectado la presencia de quenopodiáceas y asteráceas ligulifloras, liliáceas, malváceas y la presencia de la Ephedra fragilis, lo que hace presumir quizás, una fase más seca en esta zona durante la ocupación calcolítica del asentamiento y en sus alrededores más llanos (López, 1988; Walker, 1981).

Finalmente, en el área de la Depresión prelitoral murciana, en el Campo de Totana, los análisis polínicos efectuados en el abrigo funerario eneolítico de Las Carboneras proporcionaron un índice mayor de cobertura forestal, frente a la vegetal herbácea, destacando la presencia de Pinus halepensis, Quercus ilex o encina/carrasca, Pistacea lentiscus o lentisco, Olea o acebuche/olivo, Ephedra y Artemisia. Cabe mencionar que se encontró madera de Juglans regia o nogal (López, 1988).

De todo lo expuesto hasta ahora, se deduce hipotéticamente que durante este período existió una variedad vegetal más evolucionada que en la actualidad, con unas especies que se desarrollaron en los distintos medios climáticos, siempre por lo general, mucho más húmedos que los existentes hoy en día, aunque en las cotas por debajo de $600 \mathrm{~m}$., el clima pudo ser cálido mediterráneo, en tanto que en las cotas de montaña media, 700/1600 m., el clima sería submediterráneo templado, especialmente en las ticrras interiores. Un paisaje, por tanto, bastante distinto a la aridez actual y que, sin embargo, algunos geógrafos y prehistoriadores creen sea producto de un proceso sin solución de continuidad, a partir del III milenio y etapas posteriores.

Por otro lado, la línea de costa también ha sufrido diversas alteraciones durante los últímos cinco mil años. Las recientes perforaciones geológicas efectuadas por el Instituto Arqueológico Alemán de Madrid y el Departamento de Geología de la Universidad de Kiel, a lo largo del litoral de la Andalucía mediterránea, han confirmado que la línea de mar penetraba más al interior; así, en las actuales tierras aluviales de la desembocadura del río Almanzora, hubo una ría o amplia ensenada de unos $4 \mathrm{kms}$. de longitud interior y una anchura de 1/1,5 kms. Por tanto, el asentamiento de Almizaraque se situaba en un pequeño promontorio terrestre o minúscula península, al pie mismo del mar. La desembocadura del río Antas, a su vez estuvo ocupada por una amplia ensenada o bahía constituida por diversas pequeñas penínsulas, con una penetración de $3 \mathrm{kms}$. tierra adentro y una amplitud de unos $2 \mathrm{kms}$. (Arteaga et alii, 1987). Otro tanto debe suceder con la desembocadura del río Andarax o Almería, todavía por confirmar a causa de la potente sedimentación aluvial que llega a los $90 \mathrm{~m}$. de potencia, pero que a la altura de la población de Pechina, y dado que en época musulmana pudo existir un puerto según la tradición, también es probable que existiera una amplia ría en sus inicios que se iría estrechando a medida que penetraba hacia el interior, lo cual obliga a plantearse si en época calcolítica el yacimiento de Los Millares pudo estar próximo y más conectado a la línea litoral. Otro tanto sucedería con la rada que pudo existir en la desembocadura del río Adra y de cuyos sondeos geológicos nada sabemos por el momento.

En conjunto, podemos establecer una hipótesis general con respecto a un modelo de paisaje geográfico en estas regiones meridionales de la Andalucía mediterránea, y muy distinto al existente actualmente, tanto en lo que concierne a la geomorfología del interior, como de la costa. La dinámica erosiva no habría todavía incidido durante el período calcolítico tan profudamente como hoy en día; los cauces fluviales mantendrían una .aportación hídrica constante; los llanos y vertientes 
montañosas poseerian una cobertura vegetal de bosque abierto mixto y las condiciones climáticas variarian según zonas en microclimas locales con niveles de mayor o menor humedad y con unas isoyetas más importantes que las actuales, aunque tal vez también existieron periodos más o menos cíclicos y alternos de humedad-sequedad.

Por todo ello, el papel dominante en el territorio cultural de Los Millares correspondería a una vegetación arbolada cuyo mecanismo de autorregulación no fue lo suficientemente intenso como para compensar la alteración humana. La diversidad de relieves y climas daría origen a factores ambientales distintos, aunque basados en dos grandes dominios, el cálido tendente a seco moderado, de tipo estacional, en las zonas costeras, y el más templado, tendente a húmedo submediterráneo en las zonas más bajas del interior, quizás en la Depresión prelitoral, y húmedo tendente a frío en los altiplanos y serranías del interior; todo ello condicionado siempre por la topografía y la altimetría de cada comarca natural.

La falta de más datos polínicos, antracológicos, faunisticos y geomorfológicos, no permite hoy por hoy establecer con cierta garantía científica unas hipótesis de reconstrucción paleogeográfica y paleoambiental, pero aún con la escasa información que poseemos, todo parece indicar que hemos de considerar con muchas probabilidades la existencia de radicales cambios biogeográficos en las tierras que ocupó el grupo cultural de Los Millares.

\section{BIBLIOGRAFIA}

ARteaga, O; Hoffman, G.; Schubart, H. y Schultz, H. D. (1987): «Investigaciones geológicas y arqueológicas sobre los cambios de la línea costera en el litoral de la Andalucía mediterránea. Informe preliminar (1985)». Anuario Arqueológico de Andalucia, II: 117-122.

BAKER, A. R. H. (1972): Progress in Historical Geography. David \& Charles (ed.). London.

BAKER, J. N. L. (1952): "The Development of Historical Geography in Britain during the last Hundred Years". Advancement of Science, 8: 406-412.

BARTELS, D. (1968): Zur wissenschaftstheoretichen Grundlegung einer Geographie des Menchen. Steiner, Wiesbaden.

Barrows, H. H. (1923): «Geography as Human Ecology». Annals of the Association of American Geographers, 13: $1-14$.

BAYLEY, G. N. (1983): «Hunter-gatherer behaviour an prehistory: problems and perspectives». En G. Bailey (Ed.). Hunter-gatherer Economy in Prehistory. Cambridge University Pres, Cambridge: 1-6.

Berry, B. J. L. y Pred, A. (1961): Central Place Studies. Regional Sciences Research Institute. Bibliography Series 1. Philadelphia.

Binford, L. R. (ed.) (1977): For Theory Building in Archaeology. Academic Press, New York.

Birot, P. y SolÉ SABARIS, L. (1959): «Recherches sur la morphologie du sud-est de l'Espagne». Revue Gèographique des Pirénées et du Sud-Ouest, XXX: 45-62.

BовеK, H. (1942): "Geographie und Raumforschung Grundsatzliche Betrachtungen». Raumforchung und Raumordnung 6. H., 10-11: 336-345.

- (1948): «Stellung und Bedentung der Sozialgeographie». Erdkunde II, 1-3: 118-125.

BunGe, W. (1962): "Theoretical Geography». Lund Studies in Geography, I. The Royal University of Lund.

Burillo, F. (1979): «Modelos sobre la utilización del medio geográfico en época ibérica en el valle medio del Ebrow. Memorias de Historia Antigua III (III Coloquio, Oviedo): 33-44.

- (1982): «La jerarquización del hábitat de época ibérica en el valle medio del Ebro. Una aplicación de los modelos locacionalesw. IV Jornadas sobre el Estado actual de los Estudios sobre Aragón (Alcañiz, 1981): 215228. Zaragoza.

- (1984): "La aplicación de los modelos del lugar central a la arqueología». Primeras Jornadas de Metodología de Investigación Prehistórica (Soria, 1981): 431-444. Madrid.

BuRILlo, F. y PENA, J. (1984a): «Clima, geomorfología y ocupación humana. Introducción a un plantamiento metodológicow. Primeras Jornadas de Metodología de Investigación Prehistórica (Soria, 1981): 91-104. Madrid.

- (1984b): «Modificaciones por factores geomorfológicos en el tamaño y ubicación de los asentamientos primitivos». Arqueología Espacial 1, S.A.E.T.-C.U.T.: 91-106. Teruel.

BuSCH-ZANTNER, R. (1937): «Ordnung der Anthropogenen Faktoren». Petermanns Geographischen Mitteilungen, 83: $138-141$.

ButuING, R. A. (1966): «Historical Geography and Local Studies in Ireland». Geographical Viewpoint, 1: $141-154$.

\section{T. P., 1991, $\mathrm{n}^{0} 48$}


Buttimer, A. (1967): «Reflèxions sur la Géographie Sociale». Societè Géographique du Liege, 3: $27-47$.

- (1968): «Geografía social». En D. L. Sills (dir.): Enciclopedia Internacional de las Ciencias Sociales, V: $127-136$. Aguilar Ed. Madrid.

Butzer, K. W. (1971): Environment and Archaeology: an Ecological Approach to Prehistory. Aldine Publishing Company. Chicago.

- (1982): Archaeology as Human Ecology. Cambridge University Press. (Trad. castellana Ed. Bellaterra, Barcelona, 1989).

CAPEL, H. (1983): «Positivismo y antipositivismo en la ciencia geográfica. El ejemplo de la geomorfología». Geocrítica, 43. Universidad de Barcelona.

Cerrillo, E. y Fernández, J. M. (1980): „Contribución al estudio del asentamiento romano en Extremadura. Análisis espacial aplicado al S. de Trujillow. Norba, 1: 1957-1975.

Clark, A. H. (1954): «Historical Geography». En P. E. James \& C. F. Jones (eds.). American Geography: Inventory and Prospects. Syracuse University Press. Syracuse: 70-105.

Clarke, D. L. (ed.) (1977): Spatial Archaeology. Academic Press. New York.

Claval, P. (1974): Evolución de la Geografía Humana. Ed. Oikos-Tau. Vilassar de Mar.

- (1973): Principes de Géographie Sociale. Librairies Techniques. Paris.

Cuenca PayÁ, J. y Walker, M. J. (1977): «Paleogeografía humana del Cuaternario de Alicante y Murcia». Actas de la II Reunión Nacional del Grupo de Trabajo del Cuaternario (Murcia, 1975): 65-77.

Chorley, R. J. y HAGget, P. (1967): Socioeconomic Models in Geography. Methuen. London. (Trad. castellana. Instituto de Estudios de Administración Local. Madrid, 1971).

ChristalleR, W. (1933): Die zentrale Orte in Süddeutschland. Eine okonomischwicklung der Siedlung mit stadtischen Funktionen. Jena. (Trad. inglesa, Central Places in Southern Germany. Englewood diff. PrenticeHall. New York, 1966).

- (1938a): «Rapports fonctionnels entre les agglomerations urbaines et les campagnes». Comptes Rendus 2. Congrès International de Géographie (Paris, 1936): 123-138.

- (1938b): «Siedlungsgeographie und Kon munalwissenschaft». Petermanns Geographische Mitteilungen 84, H 2: $35-43$.

Davidson, I. (1983): «Site Variability and Pr shistoric Economy in Levanten. En G. N. Bayley, (ed.) Hunter-gatherer Economy in Prehistory. Cambridge Uni 'ersity Press, Cambridge: 79-95.

DAvidSon, I y BAyLeY, G. N. (1984): «Los yacimientos, sus territorios de explotación y la topografia». Boletín del Museo Arqueológico Nacional, II, 1: 24-46.

Davis, W. M. (1912): «L'esprit explicative dans la Géographie». Annales de Géographie, 21: 1-9.

Demangeon, A. (1942): "Une definition de la Géographie Humaine». En J. Randle (ed.): Problemes de la Geographie Humaine. Paris: 25-40 (trad. castellana Ed. Omega. Barcelona, 1956: 9-28).

De Val Caturla, E. (1948): «El poblado del Bronce I mediteráneo de El Campico de Lébor, Totana (Murcia)». Cuadernos de Historia Primitiva, 1: 23-52.

DEN DRIESCH, A. vON, (1973): „Fauna, klima und landschaft in Südden der Iberischen Halbinsen Während der Metallzeit». En J. Matolcsi (ed.): Domestikation Forschung und Geschichte der Austiere. 245-254.

Den DRIESCH, A. von y MoRALES, A. (1977): «Los restos animales del yacimiento de Terrera Ventura (Tabernas, Almería)». Cuadernos de Prehistoria y Arqueología, 4: 15-34.

Everson, J. A. y FitzGerald, B. P. (1969): Settlement Patterns. Longman ed. London.

Fernández Martínez V. y Ruiz Zapatero, G. (1984): «El análisis de territorios arqueológicos: una introducción crítica». Arqueologia Espacial 1. S.A.E.I.-C.U.T. Teruel: 55-72.

Ferrer Palma, J. E. (1980): «El marco geográfico del Megalitismo en la provincia de Granada». Baetica, 3: 91 -99.

FRENCH, R. A. (1968): "Historical Geography in the USSR". Soviet Geography: Review and Traslation, 9: $551-553$.

GEORGE, P. (1966): Sociologia y Geografía. Ed. Península. Barcelona (2.a ed. 1974).

GoḾEz, J.; MuNoz, J. y ORTEGA, M. (1982): El pensamiento geográfico. Alianza Editorial. Madrid.

Gourou P. (1973): Pour une Géographie Humaine. Flamarion. Paris. (Trad. castellana Alianza Editorial, Madrid, 1979).

HAGGET, P. (1965): Locational Analysis in Human Geography. Arnold Ed. London. (Trad. castellana Gustavo Gili Ed. Barcelona, 1976).

HAHN, H. (1957): «Sozialgruppen als Forschungsgegenstand der Geographie. Gedanken zur Systematik der Anthropogeographien. Erdkunde, XI, H 1: 35-41.

Hall, R. B. (1935): "The Geography Region: A Resume». Annals of the Association of American Geographers, XXV: 129-153.

HARD, G. (1973): Die Geographie. Eine Wissenchaftheoretiche Einfuehrung. Walter de Gruyter ed. Berlin-New York.

HARRIS, R. C. (1967): "Historical Geography in Canada». Canadian Geographer, 11: 235-250.

HARTKE, W. (1959): "Gedanken zur Bestimmung von Raeumen Gleichersozialgeographischen der Haltens». Erdkunde, XIII, A 4: 426-436.

HARVEY, D. (1969): Explanation in Geography. Arnold ed. London. (Trad. castellana, Alianza Editorial. Madrid, 1983).

Hawley, A. (1962): Human Ecology. The Ronald Comp. New York. (Trad. castellana Ed. Technos, Madrid, 1975). 
Hettner, A. (1927): Die Geographie ihre Geschichte, ihre Wessen und ihre Methoden. F. Hierte Ed. Breslau.

Higgs, E. S. y Vita-Finzl, C. (1972): «Prehistory Economies: a territorial approach». En E. S. Higgs (ed.): Papers in Economic Prehistory. Cambridge University Press, Cambridge: 27-36.

Hodder, I. y Orton, C. (1976): Spatial analysis in archaeology. Cambridge University Press, Cambridge (Trad. castellana en Ed. Crítica. Barcelona, 1990).

HoKE, G. H. (1907): «The Studie of Social Geography». Geographical Journal, XXIX, 1: 64-67.

Hotres, K. H. (1970): «Die Stellung der Sozialgeographie im gefügge der Geographischen Wissenschaft». Geographical Papers, 1: 113-126.

Johnson, G. A. (1972): «A Test of the Utility of Central Place. Theory in Archaeology». En P. J. Ucko, R. Tringham y J. Dimbleby (eds.). Man Settlements and Urbanism. Duckworth, London: 769-785.

LACASA, E (1966): «El marco geográfico de la necrópolis argárica de Alquife». Noticiario Arqueológico Hispánico, VIII-IX: 135-151.

LAUTENSACH, H. (1964): Iberische Halbinsel München. (Trad. castellana. Barcelona, 1967).

Le Play, F. (1877-79): Les ouvriers européens. 6 vols. 2. a ed. Paris.

LÓPEZ, P. (1988): «Estudio polínico de seis yacimientos del sureste español». Trabajos de Prehistoria, 45: 335-345.

LOsCH, A. (1954): The economics of location. Yale University Press. (Trad. castellana en El Ateneo. Buenos Aires, 1957).

LULL, V. (1983): La cultura de El Argar. Ed. Akal, Madrid.

- (1984): «Ecología argárica». Anales de la Universidad de Murcia, XLIII, 3-4: 21 -47.

Morales MuNIz, A. (1990): «Arqueozoologia teórica: usos y abusos reflejados en la interpretación de las asociaciones de fauna de yacimientos antrópicosw. Trabajos de Prehistoria, 47: 251-290.

MoRRIL, R. L. y DORTMIzer, M. J. (1979): The Spatial Order: an Introduction to Modern Geography. Wadsworth Ed. Belmont, California.

PAREJA LOPEZ, E. (1976): «Geografía argárica granadina». Cuadernos de Prehistoria de la Universidad de Granada, 1: $125-137$.

Planhol, X. DE (1968): Les fondements géographiques de l'histoire de l'Islam. Flammarion. Paris.

Puyol ANTolín R. (1975): Almería, un área deprimida del SE español. Estudio geográfico. Instituto de Geografía Aplicada del Patronato Alonso Herrera. CSIC. Madrid.

QuAiNI, M. (1981): La construcción de la geografia humana Oikos-Tau. Vilassar de Mar.

RATZEL, F. (1882): Anthropogeographie I. Grundzüge der Anwendung der Erkunde auf die Geschichte. Stuttgart.

- (1891): Anthropogeographie II. Die Geographische Verbreitung der Menschen. Stuttgart.

- (1898-99) «Le Sol, la Societé et l'Etat*. L'Anné Sociologique, III: 1-14.

Redman, C. L. (1978): «Mesopotamiam Urban Ecology: the Systemic Context of the Emergence of Urbanisme». En C. L. Redman, J. M. Berman, E. V. Curtin, W. T. Langhorne, N. M. Versaggi y J. C. Wanser (eds.): Social Archaeology. Beyond subsistence and dating. Academic Press. New York: 329-348.

Richthofen, F. von (1883): Aufgaben und Methoden der Heutigen Geographie. Academiche Antrittsrede, Gehalten in der Aula der Universitát Leipzig am 27 April 1883. Leipzig: 36-65 (trad. castellana en Didáctica Geográfica, 3, Murcia, 1978: 49-62).

ROCHEFORT, R. (1963): "Geographie Sociale et Sciences Humaines". Butlletin de l'Association des Geographers Françaises, 314-315: 19-32.

Rodríguez BlanCo, J. (1977): «Relación Campo-Ciudad y organización social en la Celtiberia Ulterior (siglo II a. c.)». Memorias de Historia Antigua, 1. Universidad de Oviedo: 170-176.

TnSEló Verger V. (1968-69): "División comarcal de la provincia de Murcia». Papeles del Departamento de Geografia, 1. Universidad de Murcia: 11-12.

Rosenfeid, CH. L. (1972): «A Simulation Model for Landslide Prediction: an Exemple from the Coast of Normandy, Francew. En W. P. Adams \& F. M. Helleiner (eds.): International Geography 1972. Papers Submitted to the 22nd International Geographical Congress. (Canadá, 1972). University of Toronto Press, I: 98-100.

Rossi, I. y O'Higgins, E. (1980): Theories of culture and Antropological methods in People in Culture. A Survey of Cultural Anthopology. J. F. Bergin Publi. Inc. New York. (Trad. castellana, Ed. Anagrama, Barcelona).

RüHL, A. (1938): Einführung in die Allgemeine Wirtschaftsgeographie. A. W. Sighoff's, Vitgeversmaatg-Chappij, N. V. Leiden.

Ruiz, A. y Molinos, A. (1984): «Poblamiento ibérico de la Campiña de Jaén. Análisis de una ordenación del territoriow. Primeras Jornadas de Metodología e Investigación Prehistórica (Soria, 1981): 421-430. Madrid.

RUPPERT, K. y SCHAEFFER, F. (1969): «Acerca de la concepción de la geografía social». Geo-crítica 21, Universidad de Barcelona (1979).

Sahlins, M. (1974): Stone Age Economics. Aldine Publi. Comp. Chicago (Trad. castellana Akal Ed. Madrid, 1977).

SAVER, C. O. (1927): «Recents Developments in Cultural geographie». En E. C. Hayes (ed.): Recents Developments in Social Sciences. Lippincot, Philadelphia: 154-212.

SCHLÜETER, O. (1906a): Die Ziele der Geographie des Menschen. R. Eoldenburg. München-Berlin.

- (1906b): «Die Leitenden Geschichtstunkte der Anthropogeographie, Inbesondere der Lehre Friederich Ratzel». Archiv für Sozialwissenschaft und Sozialpolitik, 22: 581-630.

SHOELLER, P. (1969): Allgemeine Stadtgeographie. Wissenschaftliche Buchgesellschaft. Darmstadt.

T.P., 1991, ne 48 
SChUBART, H. (1991): «Almizaraque y Zambujal como plazas portuarias de la Edad del Cobre». En Homenaje a D. Emeterio Cuadrado: 22-26.

Seminario de Aroueología y Etnología Turolense-Colegio Universitario de Teruel (S.A.E.T.-C.U.T.) (1984): Arqueologia Espacial Coloquio sobre Distribución y Relaciones entre los Asentamientos (Teruel): 1 a 6.

- (1986): Arqueología Espacial Coloquio sobre el Microespacio (Teruel): 7 a 11.

- (1988): Arqueología Espacial Seminario sobre Arqueologia Espacial (Lisboa-Tomar): 12.

- (1989): Arqueología Espacial Coloquio Internacional sobre Fronteras (Teruel): 13.

SorRE, M. (1962): "The Role of Historical Explanation in Human Geography». En P. L. Wagner \& M. W. Mikesell (eds.): Reading in Cultural Geography. Chicago.

TohaRIA, M. (1988): El desierto invade España. Instituto de Estudios Económicos. Madrid.

THORNES, J. B. (1978): «The Character and Problems of Theory in Contemporary Geomorphologiew. En C. Embleton de Brunsden y D. Jones (eds.): Geomorphology: Present Problems and Future Prospect. Oxford University Press, Oxford: 14-24.

THUNEN, J. H. von (1966): Von Thünens Isolate State. Pergamon. London. (Trad. del original de 1826 Der Isolierte Staat in Beziehung auf Landwirtschaft und Nationalookonomie).

UERPMANN, H. P. (1979): «Informe sobre los restos faunísticos del Corte no 1». En A. Arribas y F. Molina, El poblado de Los Castillejos en Las Peñas de los Gitanos (Montefrio, Granada). Serie monográfica, 3, Cuadernos de Prehistoria. Universidad de Granada: 153-168.

VallauX, C. (1911): Géographie Sociale: le Sol et l'Etat. Paris. (Trad. castellana. Ed. D. Jorro, Madrid, 1914).

VIDAL DE LA Blache, P. M. (1911): "Les Genres de vie dans la Geographie Humaine». Annales de Geographie, XX: 193-212 y $289-304$.

WALKER, M. J. (1981): "Climate, Economy and Cultural Change: the SE Spanish Copper Age». Miscelánea $X$ Congreso UISSPP (México, D. F.): 171-197.

- (1985): «El Prado ant the Southeastern Spanish Chalcolithic». Research Report of the National Society, XX: 799-834.

WIRTH, E. (1969a): «Zum Problem eine Allgemeine Kulturgeographie, Raummodelle, Kulturgeographiche Kräftelehre, Raumrelevante Prozesse, kategorien». Die Erde, 100. H 2-4: 155-193.

- (1969b): Wirtschaftsgeographie. Wissenschafliche Buckgesellschaft. Darmstadt.

- (1981): «Kritische Anmerkinagen zu den Wahrnehmungszentrierten forschungsansaetze in der Geographie. Umveltpsychologisch Fundierte "Behavioural Approach" Oder Sozialgeographie auf der Basis Moderner Handlungstheorien». Geographische Zeitschrift, 69. H 3: 1961, 198.

WISSLER, C. (1927): "The Culture-Area Concept in Social Anthropology». American Journal of Sociology, XXXII, May: $1-72$. 